\title{
KEARIFAN LOKAL DALAM MELESTARIKAN MATA AIR (Studi Kasus di Desa Purwogondo, Kecamatan Boja, Kabupaten Kendal)
}

\author{
Siswadi, Tukiman Taruna, Hartuti Purnaweni \\ Program Studi Ilmu Ilmu Lingkungan, Program Pascasarjana Universitas Diponegoro Semarang
}

\begin{abstract}
ABSTRAK
Air merupakan benda alam paling esensial bagi kehidupan. Namun ketersediaannya di daerah Purwogondo dan sekitarnya secara umum cenderung menurun, sehingga sering menimbulkan konflik antar pengguna air. Di Desa Purwogondo terdapat satu mata air yang debitnya cukup besar dan ajeg, yaitu Tuk Serco. Ini terkait keberadaan kearifan lokal yang berfungsi mencegah kerusakan fungsi Tuk Serco. Di tengah-tengah semakin memudarnya kearifan-kearifan lokal, ternyata masih terdapat kearifan lokal yang mampu memelihara dan melestarikan mata air. Penelitian ini menggunakan metode deskriptif kualitatif, dengan penentuan sampel sumber data secara purpossive dan snowball sampling. Data diperoleh melalui diskusi kelompok terfokus, wawancara mendalam, observasi lapangan, dan dokumentasi.Hasilnya adalah (1) masyarakat Desa Purwogondo mempersepsikan Tuk Serco sebagai karunia Allah yang sangat mendukung penghidupan, tempat yang sakral, ditunggu oleh kekuatan ghaib yang tidak boleh diganggu, harus dihormati sebagai sesama makluk ciptaan Allah. Dengan debitnya 12,03 lt/dt, atau 1.039.392 lt/hari, Tuk Serco digunakan untuk keperluan rumah tangga $106 \mathrm{KK} / 351$ jiwa dan irigasi sawah 5,75 hektar di Dusun Ngijo 527.126,4 liter (50,71\%). Sisanya 512.265,6 liter (49,29\%) belum terpakai. Manfaat lain Tuk Serco adalah untuk pengobatan, bersuci, dan kegiatan ritual. (2) Terdapat kearifan lokal penduduk Desa Purwogondo berupa: pengetahuan, nilai-nilai, etika dan moral, dan norma-norma yang berupa anjuran, larangan, dan sanksi, serta ungkapan-ungkapan yang dipakai sebagai pedoman sikap dan perilaku masyarakat dalam memelihara, menjaga dan melestariakan mata air Tuk Serco. Untuk mempertahankan debit air perlu pengelolaan hutan di sekitar mata air dan daerah atasnya. Untuk memelihara dan mempertahankan kearifan lokal, masyarakat melakukan dengan memberikan pengertian dan saran kepada keluarga, tetangga, sanak-saudara dan anak-cucu tentang nilai-nilai, etika dan moral, serta norma-norma termasuk norma agama untuk dipakai sebagai pedoman bersikap dan berperilaku dalam menjalankan tradisi dan naluri menghargai alam Tuk Serco. (3) Untuk menjaga kearifan lokal dimasa mendatang, perlu langkah-langkah : a) Penguatan semangat masyarakat b) Meningkatkan pemahaman, kesadaran, kepedulian, dan partisipasi masyarakat menuju masyarakat yang arif lingkungan c) Menyediakan payung hukum dengan Peraturan Desa d) Mendorong terciptanya Desa Purwogondo sebagai Desa Wisata Religi.
\end{abstract}

Kata Kunci: Kearifan lokal, persepsi, perilaku, melestarikan, mata air.

\section{PENDAHULUAN}

Nenek moyang kita sebenarnya telah mewariskan beragam kearifan lokal yang dipakai sebagai pedoman sikap dan perilaku dalam berinteraksi dengan alam dan lingkungan. Secara empiris kearifan lokal tersebut telah berhasil mencegah kerusakan fungsi lingkungan, baik tanah/lahan, hutan, maupun air. Contohnya adalah tradisi nyabuk gunung, susuk wangan, merti desa di Jawa Tengah, Subak di Bali, Sasi di Maluku, senguyun di Kalimantan, dsb, Namun kearifan lokal tersebut saat ini sudah mulai pudar. Akibatnya sumberdaya alam tidak lagi terpelihara dengan baik ; lahan dan hutan rusak, mata air banyak yang mati; padahal air merupakan kebutuhan paling esensial bagi makluk hidup Kekurangan air manusia, hewan, dan tumbuhan akan terganggu pertumbuhan, kesehatan, dan produktivitasnya, bahkan akan mati (Manik, 2009). Program ketahanan pangan akan sulit terwujud tanpa tersedianya air dalam jumlah yang memadai. Namun akhir-akhir ini ketersediaan air 
di Kabupaten Kendal, terutama di wilayah Kecamatan Boja dan sekitarnya secara umum menurun, sedang kebutuhan air untuk berbagai sektor semakin meningkat, sehingga sering terjadi konflik pemanfaatan air. Namun di Desa Purwogondo, terdapat mata air yang debitnya besar dan ajeg yang terpelihara secara lestari dengan keberadaan kearifan lokal yang dimilki masyarakat setempat. Dalam perspektif pembangunan berkelanjutan, kearifan lokal yang terbukti secara efektif mencegah kerusakan fungsi lingkungan, perlu digali, dikaji, dan dikembangkan.

Kearifan lokal yang sering dikonsepsikan sebagai pengetahuan setempat (local knowledge), kecerdasan setempat (local genius), dan kebijakan setempat (local wisdom), oleh UU RI No.32 Tahun 2009 tentang Perlindungan dan Pengelolaan Lingkungan Hidup dimaknai sebagai nilai-nilai luhur yang berlaku dalam tata kehidupan masyarakat yang antara lain dipakai untuk melindungi dan mengelola lingkungan hidup secara lestari; di Desa Purwogondo, telah diterapkan dalam pengelolaan mata air. Masyarakat mempersepsikan mata air Tuk Serco sebagai karunia Allah yang bermanfaat bagi kehidupan masyarakat. Baik air maupun kearifan lokal yang ada merupakan aset sangat berharga dan perlu dilestarikan. Terlebih dengan adanya kecenderungan ketersediaan air yang semakin menurun dan kebutuhan air yang semakin meningkat.

\section{METODE PENELITIAN}

Penelitian dilakukan di Desa Purwogondo, Kecamatan Boja, Kabupaten Kendal, dengan metode penelitian kualitatif, untuk mendalami situasi sosial yang mendalam.

Sebagai sampel sumber data adalah narasumber/informan/partisipan,penentuannya dilakukan secara purposive dan snowballing sampling (Sugiyono, $2008: 53-56$ ).

\section{HASIL DAN PEMBAHASAN}

\section{Terhadap Tuk Serco}

Masyarakat Desa Purwogondo mempersepsikan Tuk Serco dengan positif, al :

- Tuk Serco adalah karunia Allah yang memberikan penghidupan Tuk Serco dan segala isinya adalah ciptaan Allah, makluk Allah, dan ada karena kehendak Allah.
- Tuk Serco mempunyai kekuatan ghaib/ roch penunggu, sakral, suci, dan angker, tidak boleh diganggu, harus dihormati, dan dihargai.

- Di areal Tuk Serco terdapat arca yang tidak kasad mata, jika diambil (dipercaya) air itu akan mati.

- Tuk Serco debitnya besar dan ajeg, oleh karena memberi berkah kehidupan bagi warga, baik untuk keperluan rumah tangga, mengairi sawah, maupun untuk obat dan tempat ritual. Jika Tuk Serco mati, maka sawah akan kering dan keperluan air untuk rumah tangga terlantar.

Dengan debit 12,03 lt/dt atau $1.039 .392 \mathrm{lt} / \mathrm{hari}$

Tuk Serco digunakan untuk :

- $\quad$ Rumah tangga $=86,4$ lt/orang/hari

(Notohadiprawiro, 2006:3).

Dengan 351 jiwa $=351 \times 86,4$ lt $\times 1$ hari $=$ 30.326, $4 \mathrm{lt} /$ hari.

- Pengairan sawah = $1 \mathrm{lt} / \mathrm{dt} / \mathrm{ha}$ (Notohadiprawiro,2006:2).

Dengan 5,75 Ha = 5,75 Ha x 60 lt x 60 menit x 24 jam $\times 1$ lt $=496.800$ liter. Dengan demikian air terpakai untuk rumah tangga dan irigasi adalah 527.126,4 lt.

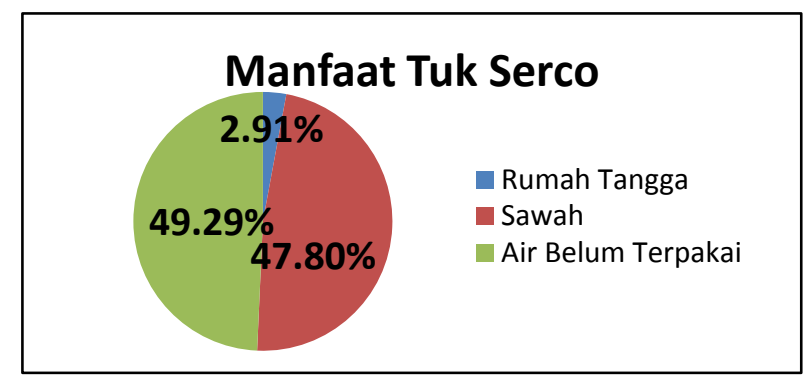

Gambar 1. Diagram Manfaat Tuk Serco

Manfaat lain dari Tuk Serco adalah untuk Jamban, tempat mencari ikan, perikanan, pengobatan, bersuci/berwudlu, dan kegiatan ritual.

\section{Kearifan Lokal Penduduk Desa Purwogondo}

Kearifan lokal masyarakat Desa Purwogondo berupa :

1. Pengetahuan masyarakat, yang berupa ilmu titen.

2. Nilai-nilai : nilai-nilai kebersamaan, kepatuhan, kemufakatan, keadilan, dan kepedulian.

3. Etika dan moral : mewujud dalam sikap dan perilaku arif lingkungan, sopan, bertanggungjawab secara moral atas keberadaan dan kelestarian Tuk Serco, tidak merusak, tidak mengancam eksistensi Tuk Serco. Masyarakat 
menyadari bahwa Tuk Serco dan segala isinya adalah sebagai sesama makluk Allah yg harus dihargai dan dihormati.

4. Norma-norma, berupa : anjuran-anjuran, larangan-larangan, sanksi-sanksi, dan ungkapan-ungkapan.

Norma yang berupa anjuran, a.l :

- Menjaga kebersihan lingkungan mata air

- Mengadakan upacara ritual selamatan/sedekah dan sesaji dilokasi mata air sebagai wujud penghargaan karena tuk serco telah memberi manfaat yang besar bagi kehidupan warga,

- Menepati janji tradisi sesaji yang harus baik, banyak, dan ikhlas.

- Membiarkan kondisi tuk serco apa adanya, tidak mengubah-ubah.

Norma yang berupa larangan, a.l.:

- Tidak boleh mencuci perkakas dapur yang berjelaga, mencuci daging yang berdarah dengan membelakangi mata air, mencuci bekas tempat masakan, bekas tempat ikan.

- Tidak boleh jahil dan takabur.

- Dilarang membuang sampah

- disekitar mata air.

- Tidak boleh merubah posisi atau mengambil benda/barang yg ada di areal mata air.

- Tidak boleh membangun disekitar mata air (baik darurat, semi permanen, maupun permanen).

- Tidak boleh menyalur air diatas sendang dan pancuran.

Ungkapan-ungkapan, al. :

- “Urip kuwi bakal bali marang sangkan paraning dumadi", artinya bahwa orang hidup itu akan kembali kepada Sang Penciptanya dan harus mempertanggung jawabkan perbuatannya. Oleh karena manusia tidak boleh merusak alam.

- " Ning endi ono wong usil, ning kono ono bencana", yang artinya dimana ada orang usil, disitu ada bencana.

Sanksi-sanksi, berupa :

- Sanksi fisik (sakit secara fisik: kejang-kejang, lumpuh, dll).

- Sanksi non fisik (berupa gangguan kejiwaan).

- Sanksi sosial (dicela, dicemooh, diolok-olok, dsb.)

(C) 2011, Program Studi Ilmu Lingkungan Program Pasca Sarjana UNDIP

\section{Kearifan Lokal Melestarikan Tuk Serco}

- Kearifan lokal yang berupa nilai-nilai, etika dan moral, dan norma-norma, dipakai sebagai pedoman sikap dan perilaku masyarakat dalam melestarikan mata air.

- Kearifan lokal tersebut diterapkan dalam berbagai kegiatan baik fisik (kebersihan lingkungan, perbaikan sarana, aktivitas lain) maupun non fisik/ritual (sedekah, sesaji, do'a, dll) baik rutin maupun insidentil.

- Sehingga dapat mencegah kerusakan fungsi lingkungan.

Kegiatan gotong-royong kebersihan Tuk Serco ini dilakukan secara rutin setiap bulan Maulud (Robiul awwal), pada hari Jum'at paing, dimulai jam 06.00 WIB. Kemudian dilanjutkan kegiatan ritual selamatan/sedekah dan sesaji.

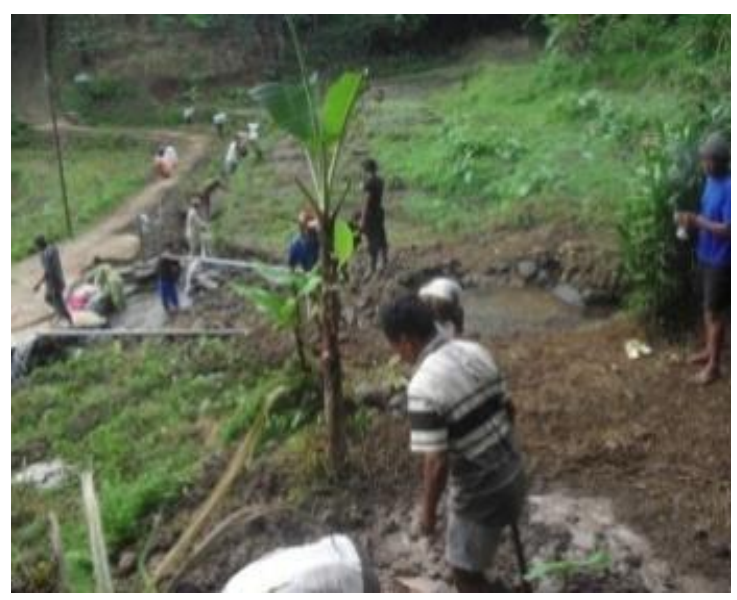

Gambar 2. Kerja bakti di Areal Tuk Serco

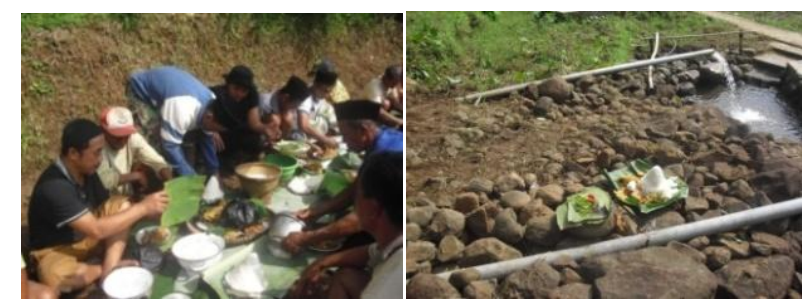

Gambar 3. Kegiatan Ritual di Tuk Serco

\section{Menjaga Kearifan Lokal Masa Mendatang}

Kearifan lokal di Desa Purwogondo terbukti efektif mencegah kerusakan fungsi lingkungan mata air secara berkelanjutan, maka harus dijaga dan dilestarikan.

Program yang diperlukan, sbb. :

a. Penguatan semangat komunitas adat dan agama. 
Untuk membangkitkan semangat, diperlukan tenaga penggerak dari pihak terkait secara terpadu (pemerintah, ahli lingkungan, dan tokoh agama).

b. Peningkatan kesadaran, pemahaman, kepedulian, dan partisipasi masyarakat menuju masyarakat yang arif lingkungan.

c. Penyediaan payung hukum.

d. Mendorong terciptanya Desa Purwogondo sebagai Desa Wisata Religi dengan Tuk Serco sebagai salah satu obyek.

Agenda kegiatan meliputi :

a. Unsur tenaga penggerak melakukan pendekatan masyarakat, tokoh adat, dan tokoh masyarakat untuk mengadakan bimbingan dan penyuluhan.

b. Merintis sistem informasi dan komunikasi lingkungan bagi masyarakat desa, sosialisasi kebijakan dan pembinaan masyarakat tentang lingkungan, perpustakaan lingkungan di desa untuk meningkatkan minat baca.

c. Penyusunan Peraturan Desa (Perdes) yang memuat hal-hal penting tentang status, kedudukan, hak dan keawajiban, peran, wewenang dan tanggung-jawab dan perlindungan masyarakat adat, dan sanksisanksi, serta pengawasan.

d. Desain optimasi dampak positif dan minimasi dampak negatif.

e. Fasilitasi dari pemerintah dari semua tingkatan, yang berupa tempat pertemuan atau diskusi, sarana lain, dan kemungkinan dana.

f. Pemberian insentif bagi yang telah berjasa mengelola lingkungan mata air, baik secara kelompok maupun perorangan.

\section{KESIMPULAN DAN REKOMENDASI}

\section{Kesimpulan}

a. Desa Purwogondo mempersepsikan alam Tuk Serco secara positif, Tuk Serco dipandang sebagai karunia Allah yang sangat mendukung penghidupan warga.

b. Masyarakat Desa Purwogondo mempunyai kearifan lokal, berupa: a) Pengetahuan, diantaranya berupa ilmu titen., b) Nilai-nilai, c) Etika dan moral,. d) norma-norma yang terdiri dari anjuran, larangan, dan sanksi, serta ungkapan-ungkapan.

Kearifan lokal tersebut dipakai dan diterapkan sebagai pedoman sikap dan perilaku dalam melestarikan mata air, dalam berbagai kegiatan fisik dan ritual, rutin maupun insidentil.

Atas dasar manfaat, masyarakat semangat untuk mempertahankan dan melestarikan tradisi yang dimilikinya.

Untuk melestarikan debit air Tuk Serco, tidak hanya dengan pemeliharaan tradisi yang ada, akan tetapi diperlukan pengelolaan hutan secara baik di sekitar mata air dan di daerah atasnya.

c. Dalam upaya menjaga kearifan lokal pada masa mendatang, maka program-programnya adalah: a) Penguatan semangat masyarakat adat dan agama, b) Peningkatan pemahaman, kesadaran, kepedulian, dan partisipasi masyarakat menuju kondisi masyarakat yang arif lingkungan, $c$ ) Penyediaan payung hukum, d) Mendorong terciptanya Desa Purwogondo sebagai Desa Wisata Religi.

\section{Rekomendasi}

a. Persepsi positif masyarakat terhadap mata air hendaknya di arahkan agar mewujud pada sikap dan perilaku yang arif lingkungan, maka diperlukan pembinaan secara rutin, dengan pertemuan-pertemuan, diskusi, pendidikan dan latihan. Kerja terpadu antara pihak-pihak terkait sangat diperlukan; pemerintah memfasilitasi baik tempat maupun pendanaannya, ahli lingkungan dengan keilmuannya, serta tokoh agama yang akan didengar petuah-petuahnya. Terbukanya hubungan masyarakat dengan pihak luar, akan berpotensi memudarkan kearifan lokal yang ada. Bantuan perpustakaan desa dibidang lingkungan akan sangat membantu memberikan pengertian bagi masyarakat.

b. Keberhasilan kearifan lokal dalam melestarikan Tuk Serco, masih dalam artian fisik apa adanya, belum pada upaya mempertahankan debit airnya. Untuk mempertahankan debit air, diperlukan pengelolaan hutan di daerah atasnya, harus ada penanaman, pemeliharaan, dan pengaturan penebangan secara selektif, karena hutan merupakan salah satu unsur penentu siklus hidrologi.

c. Untuk menguatkan semangat masyarakat, perlu kerja terpadu yaitu pemerintah, ahli lingkungan, dan tokoh agama, sebagai tenaga penggerak untuk melakukan pendekatan dan pembinaan kepada masyarakat.

d. Untuk menguatkan kearifan lokal pada masa mendatang, selain dengan pembinaan kepada masyarakat secara kontinyu, perlu dibuatkan Peraturan Desa (Perdes) yang akan mengatur hal-hal penting seperti status, kedudukan, hak dan kewajiban, peran serta dan tanggung- 
jawab masyarakat adat, perlindungan kearifan lokal dan kawasan resapan air, pengawasan dan sanksi-sanksi.

Untuk mewujudkan Desa Purwogondo sebagai Desa Wisata Religi, perlu desain dan kajian seksama agar dampak positif dapat dioptimalkan dan dampak negatif dapat diminimasikan.

\section{DAFTAR PUSTAKA}

Abdilah, Sukron, 2007.

http://www.sukronAbdilah.web.id/2007/0

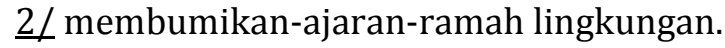
html\#

Arsyad S \& Rustiadi. E, Penyelamatan Tanah, Air, dan Lingkungan, Crestpent Pres dan Yayasan Obor Indonesia, Jakarta.

Fajri, Zul. EM dan Senja, Aprilia R, 2008. Kamus Besar Bahasa Indonesia, Difa Publisher, Jakarta.

Hadi, Sudharto. P, 2005. Dimensi Lingkungan Perencanaan Pembangunan, GadjahMada University Pres, Yogyakarta.

2009. Manusia dan Lingkungan, Badan Penerbit UNDIP, Semarang.

2008. Menumbuhkan Peran Serta Masyarakat Dalam Pengelolaan Lingkungan; Makalah Forkasi Lingkungan Hidup Limbangan.

Hamidi, 2010. Metode Penelitian Kualitataif, UMM Press, Malang.

Handoko, Marliany, 1992. Motivasi Daya Penggerak Tingkah Laku, Yayasan Kanisius, Yogyakarta.

Herdiansyah, Haris, 2010. Metodologi Penelitian Kualitataif, Salemba Humanika, Jakarta.

Hartatik, Sakti BambangW.A, Sunarningsih, 2005. Dinamika Kearifan Lokal Masyarakat Kalimantan, Ikatan Ahli Arkeologi Indonesia Komda Kalimantan, Banjarbaru.

Irianto, Maladi Agus, 2009. Mahasiswa dan Kearifan Lokal. Makalah Diskusi pada Sarasehan Kearifan Lokal Propinsi Jawa Tengah tanggal 29 Januari 2009 Oleh Badan Kesbangpol dan Linmas Propinsi Jawa Tengah, Semarang.

Irwan, Zoer'aini Djamal, 2007. Prinsip-prinsip Ekologi dan Organisasi Ekosistem, Komunitas dan Lingkungan, Bumi Aksara, Jakarta.

JKTI Programs, 2008. Jaringan Kearifan Tradisional Indonesia, Kearifan Tradisional dan Pembangunan Berkeadilan. http://jkti.org/index.php. Dikunjungi hari senin tanggal 4 Oktober 2010, Jam 16.30 WIB.

Kepres RI Nomor 32 Tahun 1990 Tentang Pengelolaan Kawasan Lindung.

Keraf, Sony, 2002. Etika Lingkungan Hidup, Penerbit Kompas, Jakarta.

Koentjaraningrat, 1986. Pengantar Ilmu Antropologi, Aksara Baru, Jakarta.

1987. Kebudayaan, Mentalitas dan Pembangunan, PT. Gramedia, Jakarta.

Kodoatie, J. Robert \& Sjarief, Roestam, 2010. Tata Ruang Air, Andi, Yogyakarta.

Lampe, Musni, 2009. Kearifan Tradisional Lingkungan, Belajar dari Kasus Komunitaskomunitas Petani dan Nelayan Tradisional. http://www.scibd.com/doc/16149372/kear ifan- tradisional. Dikunjungi hari senin, tanggal 4 Oktober 2010, Jam 16.30 WIB.

Manik, K. Edy Sontang, 2009. Pengelolaan Lingkungan Hidup, Djambatan, Jakarta.

Nasution, 1988. Metode Naturalistik Kualitatif. Tarsito, Bandung.

Notohadiprawiro, Tejoyuwono, 2006. Rasionalisasi Penggunaan Sumberdaya Air di Indonesia, Universitas Gadjah Mada, http:/www.soil.faperta.ugm.ac. $\mathrm{id} / \mathrm{tj} / 19 \mathrm{XX} / 19 \mathrm{xx} \% 20$ RASIONALISASI.pdf

PP Nomor 68 Tahun 2002 Tentang Ketahanan Pangan.

Purba, Jonny, 2005. Pengelolaan Lingkungan Sosial, Kantor Menteri Negara Lingkungan Hidup. Yayasan Obor Indonesia, Jakarta.

Purwanto, Ngalim, 1997. Psikologi Pendidikan, PT. Remaja Rosdakarya, Bandung.

Rohadi, Tasdiyanto, 2010. Ekologi Manusia, Power Point. Kementerian Lingkungan Hidup RI.Ikatan Ahli Lingkungan Hidup Indonesia.

Siagian, Sondang. P, 2008. Manajemen Sumber Daya Manusia, Bumi Aksara, Jakarta.

Soemarwoto, Otto, 2001. Atur Diri Sendiri. Paradigma Baru Pengelolaan Lingkungan Hidup. Gadjah Mada University Press, Yogyakarta.

Soerjani, Moch, Ahmat R, Munir R, 1987. Lingkungan: Sumber Daya Alam dan Kependudukan Dalam Pembangunan, Universitas Indonesia- UI- Press, Jakarta

Soetrisno, Lukman, 1995. Menuju Masyarakat Partisipatif, Penerbit Kanisius, Yogyakarta.

Suparmoko, 2008, Ekonomi Sumberdayua Alam dan Lingkungan, BPFE, Yogyakarta.

2006, Panduan dan analisis Valuasi Ekonomi Sumberdaya Alam dan Lingkungan, BPFE, Yogyakarta. 
Soemardjan, Selo, Soemardi, 1964. Setangkai bunga Sosiologi, Lembaga Penerbit Fakultas Ekonomi Fakultas ekonomi, Universitas Indonesia, Jakarta.

Tjokroamidjojo, Bintoro, 1987. Perencanaan Pembangunan, Gunung Agung, Jakarta.

UU RI Nomor 5 Tahun 1990 Tentang Konservasi Sumber Daya Alam.

UU RI Nomor 7 Tahun 2004 tentang Sumberdaya Air.

UU RI Nomor 7 Tahun 1996 Tentang Pangan.

UU RI Nomor 32 Tahun 2009 Tentang Pengelolaan dan Perlindungan Lingkungan Hidup.

Witoelar, Rahmat, 2008. Kearifan Lokal Terhadap Lingkungan Terancam Tereliminasi, http://beritaBumi.or.id/>g=beritadtl\&newsI $\mathrm{D}=\mathrm{B} 0085 \& 1 \mathrm{key}=1$. Dikunjungi hari kamis, tanggal 15 Juli 2010, Jam 16.30 WIB. 